\title{
Comparison of four diesel engines with regard to blow-by aerosol properties as a basis for reduction strategies based on engine design and operation
}

\author{
Kai-Michael Scheiber ${ }^{1}$ $\cdot$ Niclas Nowak ${ }^{2} \cdot$ Magnus Lukas Lorenz $^{3} \cdot$ Jürgen Pfeil $^{1}$ - Thomas Koch ${ }^{1} \cdot$ Gerhard Kasper $^{2}$
}

Received: 21 September 2020 / Accepted: 1 March 2021 / Published online: 28 March 2021

(c) The Author(s) 2021

\begin{abstract}
Understanding how engine design and operation affect blow-by aerosol characteristics is key to reducing the emission of particulate matter (PM) via the crankcase ventilation system. To this end, representative aerosol data from four different diesel engines are compared on the basis of brake mean effective pressure (BMEP) and engine speed. The data were obtained from comparable sampling positions, using the same sampling system and optical particle counter. The discussion is based on the narrow particle size range of $0.4-1.3 \mu \mathrm{m}$, chosen for its significance with regard to blow-by aerosol sources, as well as for the challenges it poses for separation systems. Key findings include particle size distributions (PSD) of virtually identical shape, indicating that these engines share the same aerosol sources and underlying generation mechanisms. However, absolute concentrations differed by a factor of about six, presumably due to differences in engine design, which in turn affect key parameters such as temperature, pressure and flow rates. At BMEPs $\leq 10$ bar all engines exhibited similarly low aerosol concentrations. With increasing BMEP the concentration rose exponentially. The engine with the smallest rise and the lowest total concentration featured an aluminum alloy piston, the smallest displacement, the lowest peak BMEP as well as the lowest maximum oil temperature. At maximum torque the aerosol concentration scaled fairly linearly with engine displacement. Increasing the engine speed had a minor impact on aerosol concentrations but affected blow-by flows, hence leading to a rise of aerosol mass flows. Within the limits of this comparative measurement studies, three generation mechanisms are provided for blow-by aerosols.
\end{abstract}

Keywords Crankcase emissions $\cdot$ Blow-by aerosol $\cdot$ PM $\cdot$ Optical particle counter $\cdot$ OPC $\cdot$ EEPS

\section{Introduction}

Vehicle emission standards are becoming more and more stringent, especially in terms of particulate matter (PM). Starting with a limit of $0.36 \mathrm{~g} / \mathrm{kWh}$ in 1991 , the current EURO VI restricts PM to only $0.01 \mathrm{~g} / \mathrm{kWh}$ [14]. This limit includes PM from both the blow-by as well as the tailpipe.

Kai-Michael Scheiber

Kai-Michael.Scheiber@kit.edu

$\square$ Jürgen Pfeil

Juergen.Pfeil@kit.edu

1 Institute of Internal Combustion Engines, KIT Karlsruhe Institute of Technology, Karlsruhe, Germany

2 Institute of Mechanical Process Engineering and Mechanics, KIT Karlsruhe Institute of Technology, Karlsruhe, Germany

3 Daimler Truck AG, Stuttgart, Germany
Extensive efforts in the area of exhaust after treatment have brought tailpipe PM emissions down significantly during the past few years, thereby causing the share of the crankcase in total PM to grow disproportionately. Rather than venting them into the environment, blow-by aerosols are often recirculated to the intake air path of an engine. Closed crankcase ventilation (CCV) are well-known for other deleterious effects, such as coking in the turbocharger, soiling of sensors and other components in the intake air path, poor engine performance and, indirectly, damage to the after treatment system. CCV is nevertheless used extensively in the OEM engine portfolio. A more detailed understanding of crankcase aerosol formation is therefore needed to lower these concentrations at the source.

While there is ample literature on abatement systems for crankcase emissions from a combustion engine [1, 2, 5-7, $11,16,19,22,30]$ the properties of these aerosols or their relationship with engine design and operation are rarely 
discussed in the published literature. Though it is wellestablished that total crankcase emissions typically rise with engine load and/or speed, the role of key parameters such as temperatures (of oil or coolant), pressures (in bearing zones or combustion chamber), and flows (of blow-by or engine oil) is not yet fully understood. The oil temperature [12, 17], as well as oil formulation/aging [3] have been noted as important drivers for aerosol formation. These studies also show that measured aerosol concentrations vary significantly with sampling position. Tatli and Clark [23] compared the sub-micron portion of crankcase aerosol spectra of four different engines. The spectra differed substantially both in terms of shape and concentration, but the authors acknowledge that the engines were run under different conditions. The authors noted also that internal temperatures had a substantial impact on aerosol formation.

In light of all these variables it is clear that a uniform basis of comparison is a prerequisite to meaningful interpretations of crankcase aerosol emissions. This includes keeping engine temperatures at comparable levels and using similar engine oils; aerosols should be sampled from comparable positions, preferably with the same aerosol spectrometer, using sampling and dilution systems with known particle loss functions. Such an approach was taken in the current study to help identify the relationships of engine properties and blow-by aerosol emissions.

One commonly practiced and straightforward method to characterize crankcase PM emissions is gravimetric, whereby the blow-by particles are collected on an absolute filter and evaluated for total aerosol mass per aerosol volume. This method of measurement provides an integral value of the mass collected during the entire sampling time, without any information about particle sizes or variations in time. PSD information is essential, however, for the identification of aerosol sources and reduction strategies [18].

Numerous techniques are available to characterize aerosols in terms of PSD (e.g. [15]. Among them, optical and electrical mobility spectrometers are often used (and combined) to obtain size and time resolved data across a wide range of sizes. Both are established techniques covering particle size ranges of about $0.3->10 \mu \mathrm{m}$ and 0.01 to about $0.5 \mu \mathrm{m}$, respectively. This range is relevant both for the identification of aerosol sources and the functioning of abatement systems. Another pivotal aspect for obtaining representative blow-by PSDs is to pair the particle spectrometer with an adequate sampling and dilution system, and to adapt the sampling location within the engine carefully to the volumetric rate and direction of the local blow-by flow, flow pulsations, as well as the vapor content of the blow-by, to ensure reasonably isokinetic sampling with a minimum of measuring artifacts or particle losses [20, 25]. As far as relevant for the current study these aspects are discussed in subsequent chapters.
This paper characterizes the crankcase aerosols of four commercial diesel engines with regard to PSD (by number and mass) as well as mass flow across a range of engine operating modes. Its principal aim is to connect engine design and operation with blow-by aerosol characteristics. Sampling locations were similar for all four engines, sampling methodologies were identical. The primary tool used for aerosol characterization was an optical particle counter (OPC) covering the range of 0.4 to $>10 \mu \mathrm{m}$, with supporting measurements by an electrical mobility spectrometer (EEPS) for the submicron and nano-range. Data presentation and discussion focus primarily on the particle size range critical for most abatement systems around $1 \mu \mathrm{m}$, because modern aerosol separators are very effective in handling the range above a few micrometers, while below a few tenths of a micrometer the aerosol mass rapidly becomes insignificant.

\section{Experimental}

This chapter presents the characteristics of the four diesel engines as relevant in the context of blow-by aerosol formation, as well as the operating points selected for comparison. The measuring strategy and the choice of sampling positions are introduced. Also, key characteristics of the aerosol spectrometers are summarized. Finally, we present the rational for focusing the discussion on the particle size range between 0.4 and $1.3 \mu \mathrm{m}$.

\subsection{Engine characteristics}

Four diesel engines representing the commercial vehicle engine portfolio of the Daimler Truck AG in Europe were selected for comparison. Expressly the engines were equipped with series components. Key engine characteristics are provided in Table $1[8,9,21,29]$.

Of these four engines, three are 6-cylinder heavy-duty engines from the same engine family with common design features, but differences mainly in regard to power characteristics and engine displacement. Their maximum BMEPs are nearly the same. The fourth, a 4-cylinder medium-duty engine, differs more substantially from the others in design and specifications. All four are turbocharged with commonrail fuel injection, double overhead camshafts, feature oil nozzles to cool the pistons, and a gear train connecting drive and valve train. These differences in engine design and operation are analyzed below in more detail and discussed with regard to their likely impact on blow-by aerosol production.

The blow-by flow is an important driver for aerosol transport within the engine and can therefore also become a differentiating factor between engines with regard to blow-by aerosol generation. Figure 1 compares the above four engines with regard to volumetric blow-by flows as a 
Table 1 Overview of selected engine key characteristics

\begin{tabular}{lllll}
\hline & OM934 & OM470 & OM471 & OM473 \\
\hline Cylinder & 4 & 6 & 6 & 6 \\
Displacement/L & 5.1 & 10.7 & 12.8 & 15.6 \\
Displacement volume & 1.275 & 1.783 & 2.13 & 2.6 \\
per cylinder/L & & & & \\
Bore/mm & 110 & 125 & 132 & 139 \\
Stroke/mm & 135 & 145 & 156 & 171 \\
Max. torque/Nm & 900 & 2200 & 2600 & 3000 \\
Max. torque per cylinder/Nm & 225 & 367 & 433 & 500 \\
@ speed/rpm & 1200 & 1100 & 1100 & 1100 \\
Max. BMEP/bar & 22 & 26 & 26 & 25 \\
Max. power/kW & 170 & 330 & 390 & 460 \\
@ speed/rpm & 2200 & 1600 & 1600 & 1600 \\
Turbocharger & Dual stage & Single stage & Single stage & Single stage \\
Piston material & Aluminum & Steel & Steel & Steel \\
Applicable legislation & EURO VI & EURO VI & EURO VI & EURO VI \\
First oil volume/L & 20 & 39 & 45 & 50 \\
\hline
\end{tabular}

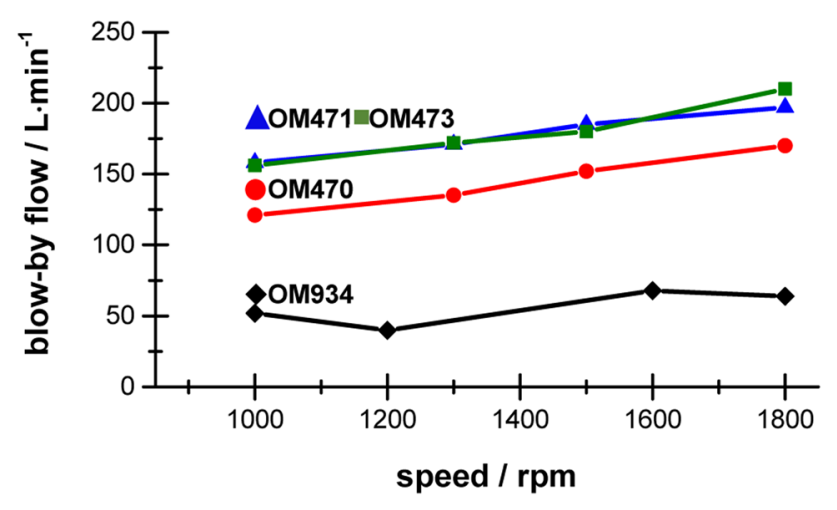

Fig. 1 Blow-by flow rates at full load with coolant inlet temperature regulated to $90{ }^{\circ} \mathrm{C}$

function of engine speed at full load. Evidently, the curves are ordered vertically by engine displacement (compare also Table 1). The volumetric flows of OM471 and OM473 are almost identical however, because the lower displacement of the OM471 is compensated by a higher power density. The OM934 curve is significantly lower due not only to a significantly lower displacement volume of that engine but also its slightly lower BMEP.

Other parameters related to engine design that may affect the aerosol characteristics include temperatures, pressures, oil properties, and engine components. For example, plain bearings act as nozzles for pressurized oil and may become sources of fine aerosol. All four engines have similar types of plain bearings at the conrod, crankshaft, camshafts and rocker shafts. However, the bearings differ in size and specific load parameters.
The turbocharger has been found to be a major contributor to oil aerosol formation in an earlier study $[4,17]$. Turbocharger units differ substantially between the four engines (Table 1): the OM934 is equipped with a dual-stage wastegate controlled turbocharger, while all other engines have a single-stage asymmetric turbocharger.

Combustion, gear train and liner concepts also differ between the four engines: the OM934 uses a swirl combustion process with an aluminum alloy piston and integrated liner. All other engines use an alternative combustion process with steel pistons and wet liners. The liner concept and liner surface affect the piston ring design, which in turn influences blow-by behavior and oil consumption. One may therefore expect these differences to affect also the aerosol production, but in a more complex way.

All four engines use the same basic concept of vertically oriented venting channels between crankcase and valve compartment. These channels are molded into the engine body and have a dual function: they serve as oil returns from the valve train back to the oil pan. At the same time, they permit blow-by gas to flow upward to the entrance of the separation system which is located just above the valve train. The four engines differ mainly with regard to the channel dimensions, with the OM934 having by far the smallest. This will increase the interaction between the two counter-flows and must be considered a factor in aerosol production.

According to Table 2, engine oils differ slightly with regard to viscosity between the medium and the heavy-duty engines, which may lead to differences in aerosol production. Densities at nominal temperature are almost identical. Given their approximately linear variation with temperature [28], the respective values for an operating oil temperature 
Table 2 Engine oil specifications (first fill), with values shown at their respective standard temperatures

\begin{tabular}{lll}
\hline & $\begin{array}{l}\text { Shell rimula } \\
\text { R6 LME }\end{array}$ & $\begin{array}{l}\text { Shell rimula } \\
\text { Ultra E Plus }\end{array}$ \\
\hline Viscosity SAE @ $17.8^{\circ} \mathrm{C} / 100{ }^{\circ} \mathrm{C}$ & $5 \mathrm{~W}-30$ & $5 \mathrm{~W}-30$ \\
$\mathrm{HTHS} / \mathrm{mPas} @ 150^{\circ} \mathrm{C}$ & 3.5 & 2.9 \\
Density/g/ml @ $15^{\circ} \mathrm{C}$ & 0.85 & 0.84 \\
Mercedes-Benz Norm MB BeVO & 228.51 & 228.61 \\
Engine & OM934 & OM470 \\
& & OM471 \\
& & OM473 \\
\hline
\end{tabular}

of $115^{\circ} \mathrm{C}$ are $0.79-0.80 \mathrm{~g} / \mathrm{ml}$. These values are used later on for calculations.

The differing levels of oil aerosol production between engines required different choices of separation system. In series configuration, the OM934 was equipped with a passive (although complex) separation system, while the heavyduty engines each featured active separators installed downstream of a passive system. Furthermore, the medium-duty engine uses a closed crankcase ventilation system, while the heavy-duty engines were operated with open crankcase ventilation. Note however, that investigating the performance of the separation systems was not the objective of this paper; crankcase aerosols were always sampled before the separation system.

In sum, there are several differences between the four engines likely to impact the aerosol production in terms of either aerosol concentration or aerosol production rate (defined as concentration multiplied by flow rate), or both. Qualitatively speaking, some of these differences (such as a higher BMEP, thinner venting channels, a dual-stage turbocharger, or a larger load on key bearings) may have an obvious tendency to increase the aerosol production rate. An increased blow-by flow (due to larger engine displacement or a different piston ring design) on the other hand, my increase the production but could also lead to more dilution, potentially leading to more aerosol mass output without however raising its concentration. The design situation is therefore too complex to make simple judgment calls with regard to emissions without extensive data.

\subsection{Strategy for engine comparisons}

All engines were incorporated in full engine test benches located either at KIT or Daimler Truck AG. In order to create comparable conditions, the following measures were taken:

Engines were operated without an air compressor, without steering pumps or other power consuming add-ons, with the standard long haul oil pan, with new engine oil at nominal oil level, with the highest available power rating EURO VI data set and without any after treatment system, but with regulated exhaust backpressure. Either the coolant inlet temperature or the oil temperature was regulated to a specific value. The air temperature after the charged air cooler was set to $40{ }^{\circ} \mathrm{C}$ at rated power.

Furthermore, the engines were compared at selected operation points spanning a wide range of aerosol production (Table 3). On the one hand, this was done at the low-end torque engine speed. The three heavy-duty engines achieve maximum torque at $1100 \mathrm{rpm}$, the medium-duty engine at 1200. Starting from this engine speed, the respective engine loads were varied between 0 and nominal BMEP. On the
Table 3 Engine operating points selected for the comparisons

\begin{tabular}{clllll}
\hline & & OM934 & OM470 & OM471 & OM473 \\
\hline $\begin{array}{c}\text { Low-end torque } \\
\text { operation point }\end{array}$ & Speed/rpm & 1200 & 1100 & 1100 & 1100 \\
& Load/\% & 100 & 100 & 100 & 100 \\
& Boundary conditions & Regulated coolant inlet temperature $90{ }^{\circ} \mathrm{C}$ & \\
Load variation & Speed/rpm & 1200 & 1100 & 1100 & 1100 \\
& BMEP/bar & 0 & 0 & 0 & 0 \\
& & 5 & 5 & 6 & 5 \\
& & 15 & 13 & 13 & 12 \\
& & 22 & 20 & 20 & 18 \\
& & & 26 & 26 & 25 \\
Speed variation & Reundary conditions & 1000 & 1000 & 1000 & 1000 \\
& Speed/rpm & 1200 & 1300 & 1300 & 1300 \\
& & 1600 & 1500 & 1500 & 1500 \\
& & 1800 & 1800 & 1800 & 1800 \\
& & 66 & 50 & 50 & 50 \\
& Load/\% & Regulated engine oil temperature $115^{\circ} \mathrm{C}$ & \\
\hline
\end{tabular}


other hand, engines speeds were varied between 1000 and $1800 \mathrm{rpm}$ at comparable loads in the intermediate range of $50-66 \%$ of the maximum while maintaining a constant engine oil temperature.

\subsection{Aerosol sampling and measurement}

\subsubsection{Sampling location on the engines}

Among the various possible locations for extracting aerosol from an engine, the one located just before the entrance to the oil mist separation system is of particular interest because it is representative for the global aerosol properties the separator(s) have to deal with. All aspects of aerosol transport, including potential particle losses or new particle formation within the preceding engine ducts are accounted for at that point. For all four engines, this point is located above the valve train in the cylinder head cover, it is relatively accessible, and therefore well suited for comparisons.

Flow conditions at the probe inlet were similar but certainly not identical. The mean flow in that region of the engine is directed upwards and the sampling probe was therefore inserted vertically into the cylinder head cover from above (Fig. 2). Sampling flow rates were adjusted to match the local mean flow velocity. Nevertheless, some modest amount of turbulence as well as flow pulsations must be expected at this (or any other) point along the blow-by path. Hence it is not possible to attain perfectly isokinetic sampling conditions. Non-ideal sampling conditions are less critical for measurements in the micron and sub-micron range. However, in the super-micron size range above a few micrometers one must expect differences between engines with regard particle losses which may severely bias engine

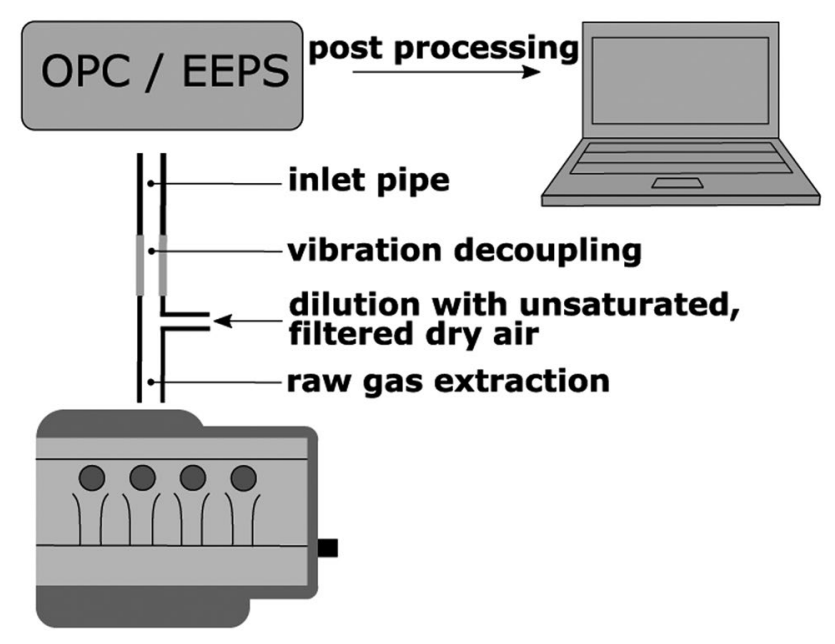

Fig. 2 Schematic overview of the measurement setup with a singlestage dilution system, vibration decoupling and optical particle counter comparisons in terms of mass. This led to the decision to exclude the size range beyond about $2 \mu \mathrm{m}$ from subsequent engine comparisons, even though OPC data were available up to $10 \mu \mathrm{m}$. (In the following, we will present additional justification for basing engine comparisons on an even narrower slice of the total particle size spectrum captured by the measurement train and particle counters.)

\subsubsection{Devices for aerosol sampling and measurement}

Among the various measurement techniques available to characterize aerosols in terms of PSD, devices with high resolution in particle size and time are most helpful for the accurate characterization of crankcase aerosols, including an accurate conversion from number concentration to mass. This study relies mostly on an optical particle spectrometer (OPC) operated nominally in the range of 0.2-10 $\mu \mathrm{m}$. Since blow-by aerosols also contain a significant sub-micron fraction not covered entirely by the OPC, additional measurements were made with an electrical mobility based particle spectrometer (EEPS). Below, key features of both devices are presented along with relevant aspects of the sampling strategy.

The OPC ('Optical Particle Counter' Model Promo 2000 HP in combination with a Welas 2070 HP detector, by Palas $\mathrm{GmbH}$ ) classifies particles optically on the basis of their light-scattering intensity in 32 size classes per decade of logarithmically equal width. Particles are classified and sorted in parallel in to size bins to obtain a PSD at the rate of $1 \mathrm{~Hz}$. The nominal maximum number concentration is $10^{6}$ particles per $\mathrm{cm}^{3}$, which necessitates dilution in case of engine aerosols. The useful upper size limit of the device is about $8 \mu \mathrm{m}$, due to inevitable particle losses in the sampling and dilution system, as explained below. The size calibration function selected for the OPC is based on the refractive index of oil.

The EEPS ('Engine Exhaust Particle Sizer' Model 3090 by TSI Inc.) characterizes particles on the basis of their electrical mobility in the nominal size range from 5.6 to $560 \mathrm{~nm}$. At first, the device imparts a defined electrical charge on the particles; it then classifies them by mobility into 16 size intervals per decade of logarithmically equal width, and finally determines the number concentration per channel sequentially by an electrometer. The EEPS offers a choice of calibrations for different particle morphologies, of which the 'compact' calibration matrix was selected as suitable for spherical oil droplets on the basis of two studies from Wang et al. [26, 27]. Comparisons using monodisperse polystyrene latex spheres showed very good agreement of the EEPS with other measurement techniques in terms of sizing accuracy [24]. The nominal upper concentration limit is $10^{7}$ particles 
per $\mathrm{cm}^{3}$ which also necessitates dilution of engine aerosols in most cases.

Given the upper concentration limits of both devices and the sampling locations before the particle separators, dilution with dry filtered air was a necessity to reduce signal coincidences and other errors during blow-by measurements. Furthermore, engine vibrations made it necessary to install a mechanical decoupling unit between sampling system and OPC, to protect the sensor from physical damage. A schematic of the sampling setup is shown in Fig. 2. Measurements on the heavy-duty engines required two-stage dilution with a ratio of 1:90; dilution for the medium-duty engine was single-stage with a ratio of 1:9. Both sampling systems had been characterized extensively for particle losses as well as the influence of condensable vapors on the measurements [20]. It was found that particle losses in the sampling systems limited reliable measurements to $8 \mu \mathrm{m}$ on the upper end while in the range of about $0.4-2 \mu \mathrm{m}$, the losses were negligible.

\subsection{Particle size range of interest for this study}

The blow-by aerosol particle spectrum is known to extend from a few tens of nanometers to hundreds of microns [13]. It would be impossible to capture the entire range with a single measuring technique. Nor would this be of real interest to the current study, which places its principal focus on the aerosol size range most difficult to deal with by oil mist separators typically built into an engine for their removal. Particle separators typically struggle most with the size range just above and below $1 \mu \mathrm{m}$, where removal efficiencies tend to have a minimum [10] while particle mass is still significant. Abatement strategies must therefore look to reduce aerosols in that size range and match separator design to dealing with the mass deposition rates coming from an engine.

A typical blow-by aerosol spectrum across the entire size range of about $10 \mathrm{~nm}$ to $10 \mu \mathrm{m}$ is shown in Fig. 3 both in terms of particle number (a) and particle mass (b) relative to the total concentration $\mathrm{C}_{\mathrm{n}}$ or $\mathrm{C}_{\mathrm{m}}$. (Note that $\mathrm{C}_{\mathrm{n}}$ and $\mathrm{C}_{\mathrm{m}}$ each represent the combined total concentration of EEPS and OPC.) The full PSD was obtained by overlapping the EEPS (red) and OPC data (blue). Although this particular data set was for the OM934 engine (at $1200 \mathrm{rpm}$ and maximum torque), it is representative for all engines studied.

According to Fig. 3a the majority of blow-by particles by relative number is located in the size range between about $0.08-0.4 \mu \mathrm{m}$. The number concentration is high and quite evenly distributed there, while to the left and right of that range it drops off rapidly. However, when converting particle number to particle mass (Fig. 3b) the contribution below about $0.4 \mu \mathrm{m}$ (i.e. in the measuring range of the EEPS) becomes relatively insignificant, while the highest mass concentrations have shifted to the range between about

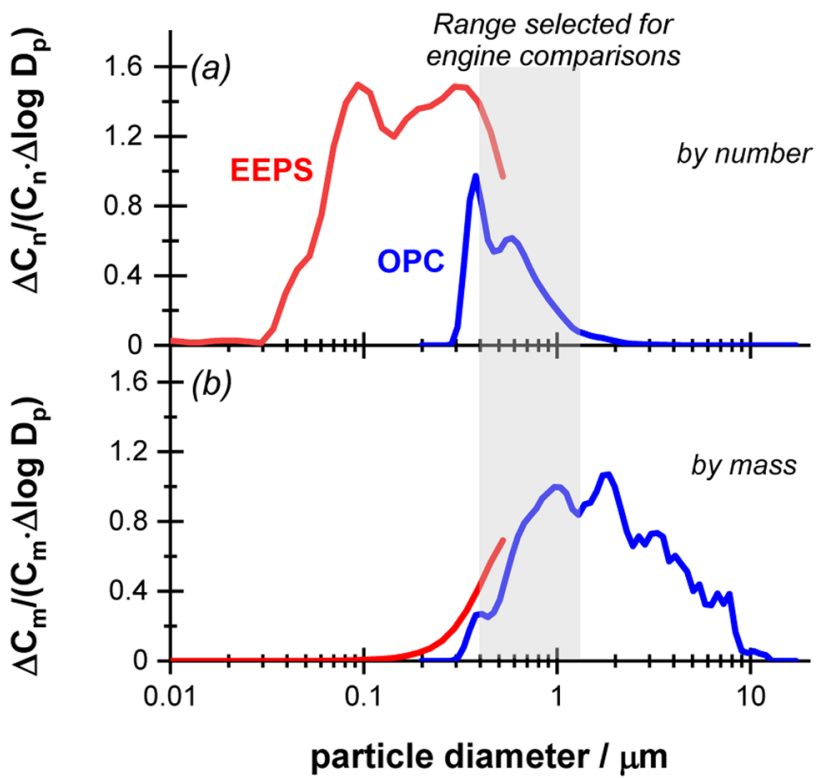

Fig. 3 Blow-by aerosol data obtained from the OM934 engine operated at $1200 \mathrm{rpm}$ and maximum torque, the figure contains plots of the number (a) and mass (b) concentrations normalized by the combined total concentration of EEPS and OPC, the vertical axis in this representation is non-dimensional

0.7 and $2 \mu \mathrm{m}$. Beyond that, the mass concentration drops off again, first gradually and then sharply above about $8 \mu \mathrm{m}$, due to inertial losses while particles are sampled and transported to the OPC. (OPC data shown here were not corrected for losses in the sampling and dilution system).

Note further that concentrations in the particle size range where EEPS and OPC overlap (between about 0.3 and $0.5 \mu \mathrm{m})$ are reasonably close, considering that the respective devices are based on entirely different principles of measurement. Moreover, the overlap region represents the size range where the both measurement techniques reach the respective limits of their performance and become less reliable for various technical reasons. The OPC in particular seems to under-represent concentrations below about $0.4 \mu \mathrm{m}$. It was therefore decided to draw a line at $0.4 \mu \mathrm{m}$, and to use OPC data only above that limit.

In conclusion, most of the blow-by aerosol mass is concentrated above $0.4 \mu \mathrm{m}$. Data above about $2 \mu \mathrm{m}$ are affected increasingly by inertial sampling losses which depend somewhat on the local flow conditions in the engine and other factors. It was therefore decided to concentrate the engine comparisons on the size window between 0.4 and $1.3 \mu \mathrm{m}$. The limit of 1.3 instead of $2 \mu \mathrm{m}$ was selected as this range represents the particle sizes most costly to separate while still containing a relevant portion of the total aerosol. It is well suited for OPC analysis and free of OPC related artifacts. One avoids the use of two measurement techniques. And particles in that range have low inertia, which facilitates 
obtaining representative aerosol samples, even when not meeting exactly isokinetic flow conditions at the probe inlet.

\section{Results}

In the following, blow-by data from the four diesel engines are compared and discussed in the context of engine design, first at maximum load, then as a function of brake mean effective pressure and engine speed. Comparisons are made on the basis of OPC data in the range of $0.4-1.3 \mu \mathrm{m}$. Concentrations are represented for each engine in terms of aerosol number as well as mass normalized by the total concentration in that range or, in some cases, by the engine producing the highest concentration. Where needed, total mass flows are calculated from the total concentration and the blow-by flow rate.

\subsection{Blow-by aerosol spectra at maximum torque}

The measurements at maximum torque were made at engine speeds of $1100 \mathrm{rpm}$ for the heavy-duty engines and $1200 \mathrm{rpm}$ for the OM934. The coolant inlet temperature was maintained at $90{ }^{\circ} \mathrm{C}$ (see Table 3). For each engine, particle size spectra are presented in terms of number and mass in the range of $0.4-1.3 \mu \mathrm{m}$. In Fig. 4 they are normalized by the total concentration of the respective engine, in Fig. 5 by the total concentration of the OM473, which has the highest blow-by concentration.

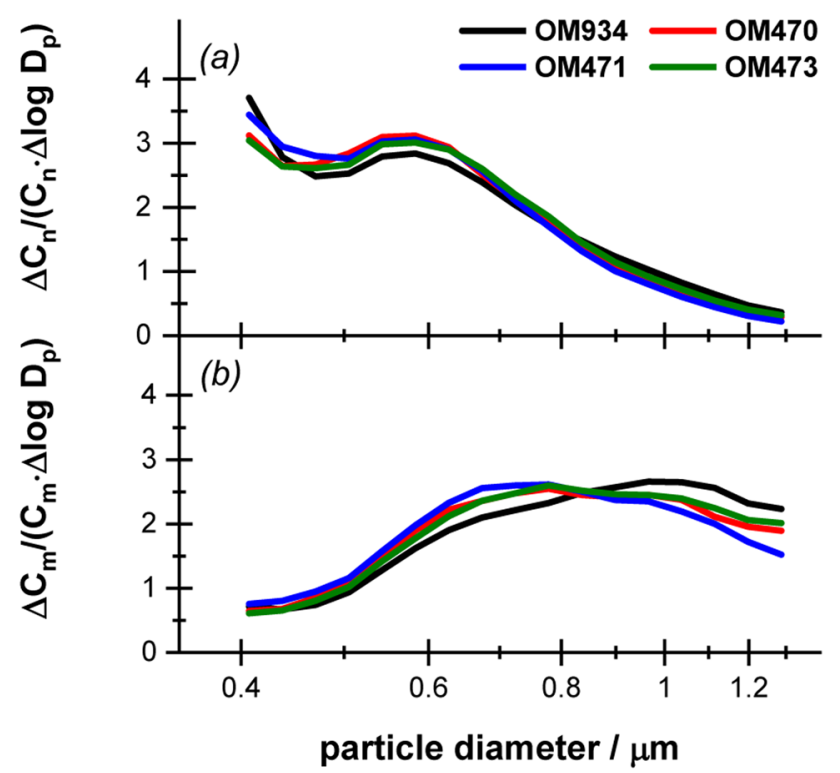

Fig. 4 Number (a) and mass (b) based blow-by aerosol PSDs at maximum torque for four engines, normalized by the respective total concentration

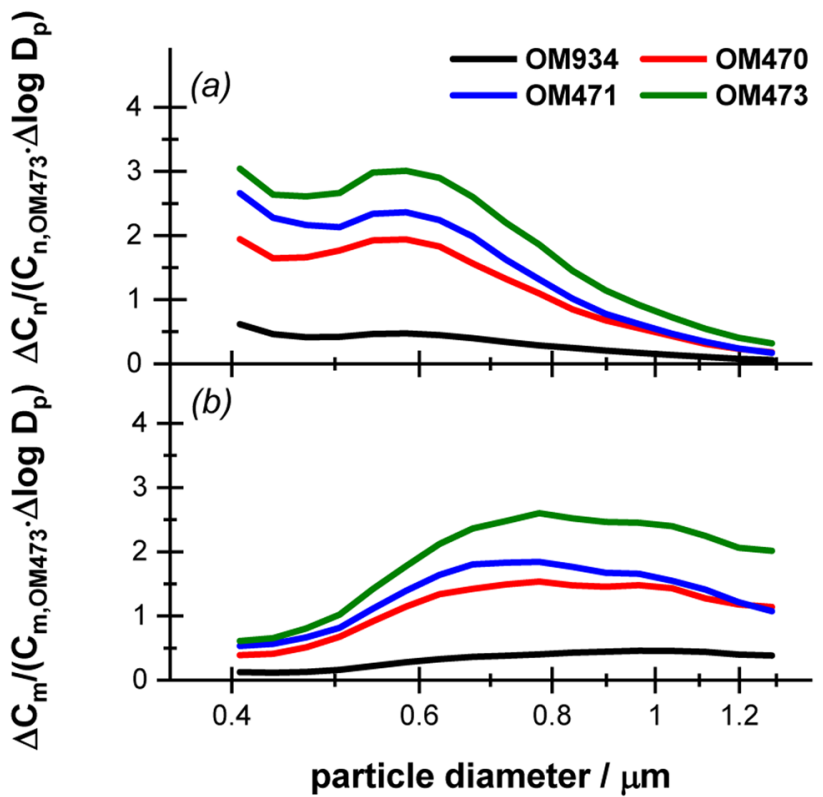

Fig. 5 Number (a) and mass (b) based blow-by aerosol PSDs at maximum torque for four engines, normalized by the total concentration of the OM473

According to Fig. 4a the number PSDs of these four engines are almost identical in shape for the size range shown. Even though the OPC captures only the tail end of the number distributions, their similarity is an indication that particle generation processes and source properties in these engines must also be very similar. The mass distributions (Fig. 4b) are also quite similar in shape, especially for the OM47x engines (red, blue, green). The mass distributions have relatively broad peaks around 0.7 and $1.0 \mu \mathrm{m}$ respectively, for the OM47x and OM934 engines. The mass based data are further indications that blowby aerosol formation mechanisms and sources in all four engines are similar at this specific working point.

When normalized by the engine with the highest aerosol output (Fig. 5), the PSD show clearly that concentration levels differ very strongly between the engines. The curves of the heavy-duty engines are more closely grouped together but still differ by a factor of almost two. The concentration of the OM473 is about six times larger than that of the medium-duty engine. Among the various differences in engine design discussed in Sect. Result, the BMEP stands out as a key candidate to explain these observed concentration differences. Notably, the mediumduty engine features a lower peak BMEP than the other three ( 22 vs. 25 or 26 bar), which may explain the reduced aerosol generation. This effect will be focused upon now. 


\subsection{Effect of BMEP on total aerosol concentration and mass flow rate}

The engine operating point affects blow-by aerosol sources directly, and ultimately also the aerosol concentrations in the crankcase of a combustion engine. In this context, one important parameter is BMEP, which is directly linked to engine torque and displacement. Comparing on the basis of BMEP permits blow-by aerosol comparisons between engines of different size and power. The effect of the BMEP on aerosol properties was investigated at engine speeds of $1100 \mathrm{rpm}$ for the heavy-duty engines and $1200 \mathrm{rpm}$ for the OM934. The coolant inlet temperature was maintained at $90{ }^{\circ} \mathrm{C}$ (Table 3). Data are now presented as total concentration (by number or mass) as well as mass flow rate. Similar to the previous figures, the data were normalized, either by the maximum concentration/mass flow of the corresponding engine (Fig. 6), or by the concentration/mass flow of the OM473 at maximum torque because this engine featured the highest aerosol output (Fig. 7). Additionally, Fig. 8 shows

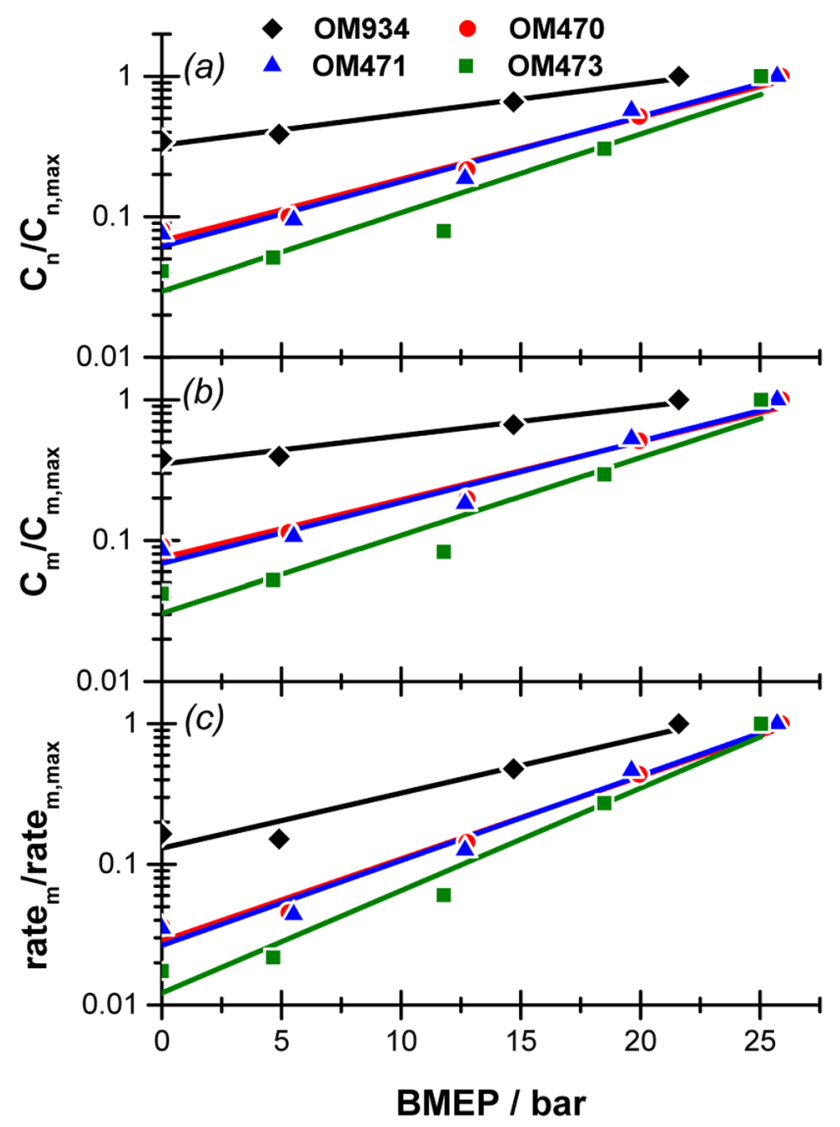

Fig. 6 Total blow-by aerosol concentrations vs. BMEP by number (a), by mass (b) and total mass flow rates (c) in the range $0.4-1.3 \mu \mathrm{m}$. Each curve is normalized by the maximum total concentration/mass flow rate of the respective engine. Regressions lines are exponential fits

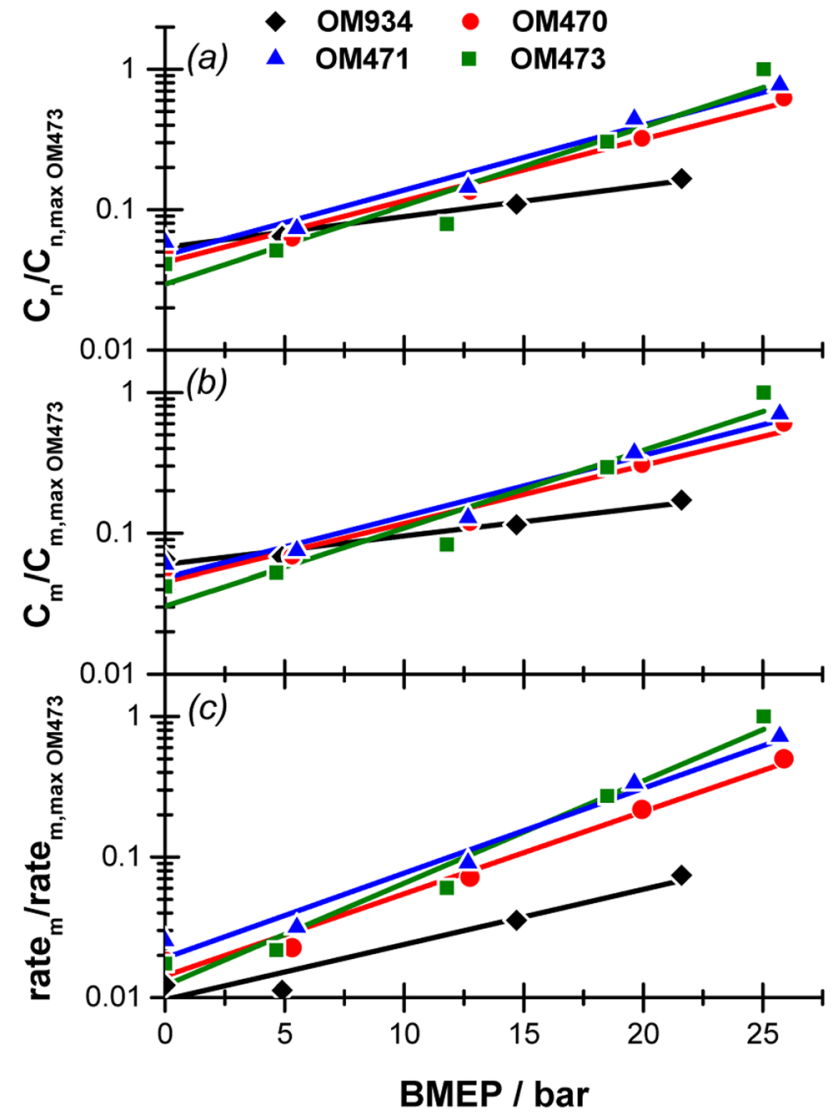

Fig. 7 Total blow-by aerosol concentrations vs. BMEP, by number (a), by mass (b) and mass flows rates (c) in the range 0.4-1.3 $\mu \mathrm{m}$. Data are normalized by the maximum emission of the OM473 engine. Regression lines are exponential fits

aerosol mass flows at maximum BMEP plotted against engine displacement.

The graphs in Fig. 6a, b (which are normalized by maximum emission of the respective engine) show clearly for all four engines that blow-by aerosol number and mass

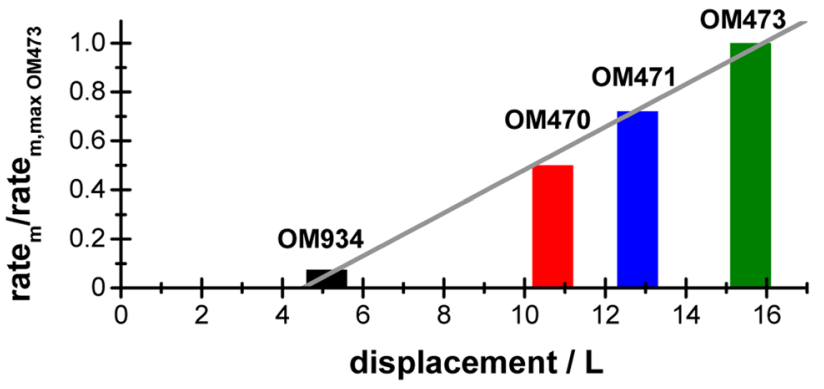

Fig. 8 Total blow-by aerosol mass flow rates vs. engine displacement in the range $0.4-1.3 \mu \mathrm{m}$. All data are normalized by the respective mass flow rate of the OM473, the engines were operated at maximum torque and speeds of either $1100 \mathrm{rpm}(\mathrm{OM} 47 \mathrm{x})$ or $1200 \mathrm{rpm}$ (OM934), gray lines are linear fit to the data 
concentrations rise strongly with BMEP (note the semilogarithmic scale). They increase by a factor of about 2 for the OM934, to more than tenfold in the case of the OM473. Mass flow rates (Fig. 6c) increase even more steeply because blow-by flow rates also increase with the engine BMEP, by factors of about 2 (OM473) to 3 (OM934). These increases can be approximated quite well using exponential fit functions. A strong dependence of crankcase emissions on engine load has been observed before e.g. by Lorenz et al. [17], who showed the bulk oil temperature to be a major factor in aerosol output. However, an exponential relationship has not yet been reported.

The curves of the three OM47x engines are not only closely grouped together, presumably due to similarities in design, but they are also significantly steeper than that of the OM934. The reasons for the flatter OM934 curve are due to much lower emissions of that engine at the highest BMEP levels, as will become evident in the discussion of Fig. 7.

Figure 7 uses the same data as the preceding figure, but now shows them normalized with respect to one engine, the OM473 engine operated at maximum torque at a speed of $1100 \mathrm{rpm}$. This presentation helps to compared absolute levels. Below about 10 bar aerosol concentrations are quite comparable for all engines tested, but toward higher BMEP the absolute differences between engines increase substantially (again note the semi-logarithmic scale). At the highest pressures (i.e. at maximum torque), the emitted concentrations of the OM473 are higher than that of the OM934 by a factor of about 5, both in number and mass. As discussed in the context of Fig. 6, this difference cannot be due entirely to differences in bulk oil temperature $\left(117^{\circ} \mathrm{C}\right.$ for the OM934 vs. $121{ }^{\circ} \mathrm{C}$ for the OM473), but may have to do with differences in piston design. While the heavy-duty engines use steel pistons, the OM934 features an aluminum alloy piston, which probably lowers thermal stress and pressure levels in the piston environment, possibly reducing aerosol generation. Similar to Fig. 6, differences between engines are even more enhanced when comparing mass flow rates (Fig. 7c) because blow-by flows of the OM934 engine are about 50\% of the OM473.

Figure 8 plots aerosol generation rates at maximum BMEP derived from Fig. 7 versus engine displacement. This operating point was chosen because each engine is specifically designed to meet the high requirements at maximum load. In other words, components (potential aerosol sources) such as pistons, bearings, and cylinder liners are dimensioned to be exposed to these high temperatures and stresses. The diagram shows a strong and fairly linear increase of the aerosol mass flow (in the critical particle size range between 0.4 and $1.3 \mu \mathrm{m}$ ) with rising engine displacement. Increasing rates were expected, as blow-by gas flows and aerosol concentrations typically rise with engine displacement at maximum BMEP. Generally, larger displacements also go along with larger amounts of engine oil circulated for cooling and lubrication purposes. Thus, potential aerosol sources such as oil spray nozzles and bearings are provided with more oil per unit time, boosting aerosol generation. Note that plotting emissions against cylinder displacement volume instead of total displacement volume (as done in Fig. 8) also leads to an approximately linear relationship, due to the fact that cylinder displacement scales with engine size (Table 1). Since such a plot provides no significant gain in insights it is not shown.

\subsection{Effect of engine speed on total aerosol concentration and mass flow rate}

The engine speed affects blow-by aerosol sources in a crankcase environment, because the kinetic energy of moving engine components is partly transformed into surface energy for the formation of new airborne droplets. To study the influence of this engine parameter on aerosol properties, measurements were made at 4 different speeds between $1000-1800 \mathrm{rpm}$. For each speed, the engine torque was fixed at $50 \%$ for the OM47x engines and $66 \%$ for the OM934 engine to keep oil temperatures constant at $115{ }^{\circ} \mathrm{C}$ for all operating points (Table 3 ). As in the previous set of graphs, the data are presented as number and mass concentrations as well as aerosol production rates. They are normalized either by the maximum total concentration / mass flow of the individual engines (Fig. 9) or by the total concentration/ mass flow of the OM471 at $1800 \mathrm{rpm}$, i.e. the engine with largest aerosol production (Fig. 10).

For each engine, Fig. 9 shows aerosol data obtained at four engine speeds. They are normalized by engine to highlight relative changes with speed for each engine. Concentration curves are relatively flat, when compared to the BMEP data seen in the previous figures. Number concentrations rise by a factor of 1.2 (OM934 and OM471) to about 2 (OM470) between 1000 and $1800 \mathrm{rpm}$; mass concentrations increase even less with a maximum variation of only 1.3 (OM470). With regard to concentration, any increase in mechanical generation of blow-by aerosols with engine speed is apparently compensated to a large extent by the diluting effect of the equally rising blow-by volume flow. This effect is a little less pronounced for the number concentration (Fig. 8a) than for the mass concentration (Fig. 9b). One can therefore suspect that the mechanical generation of aerosols increases more strongly in the sub-micron range, to which the number concentration is more sensitive. This assumption is underpinned by PSD data (not shown here). On the other hand, the aerosol mass flow rates (Fig. 9c) typically increase more systematically with engine speed because blow-by flow flushes out oil droplets from the crankcase towards the entrance of the crankcase ventilation system. 


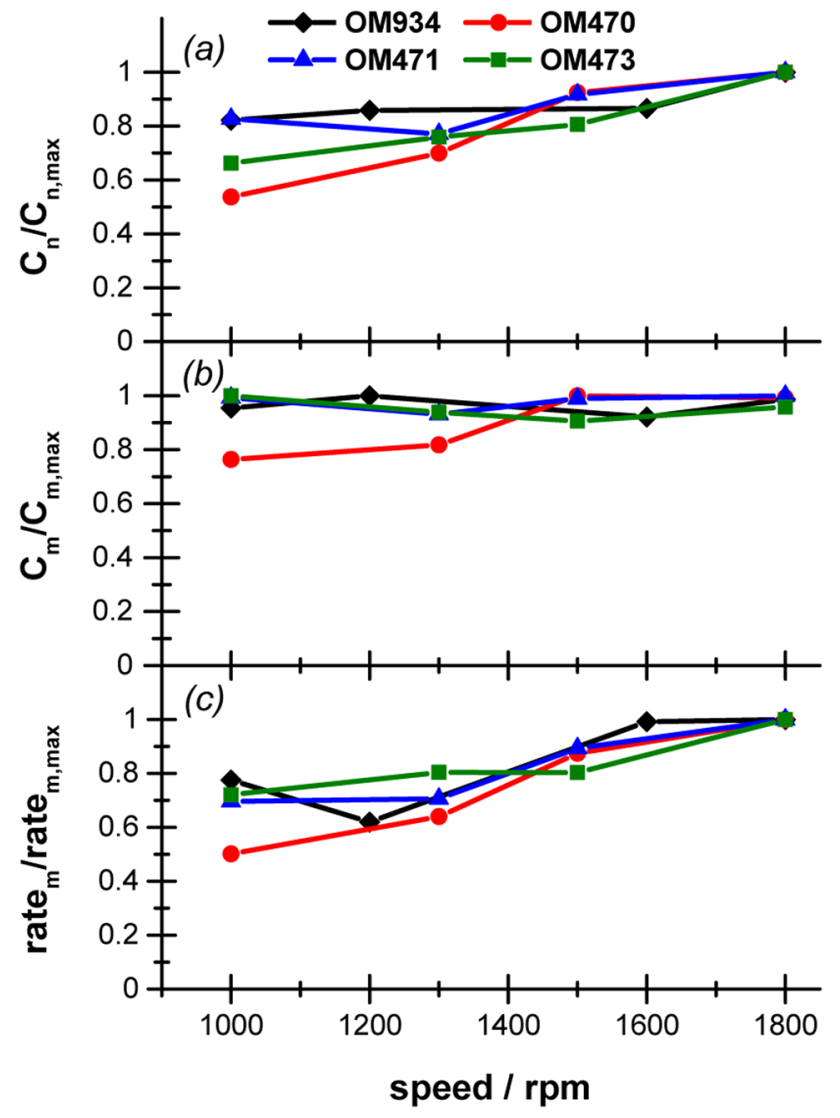

Fig. 9 Total aerosol number concentrations (a), mass concentrations (b) and mass flows (c) in the range $0.4-1.3 \mu \mathrm{m}$ vs. engine speed, data are normalized by the maximum total concentration/mass flow rate of each engine, data points are connected by straight lines as a guide to the eye

It is interesting to note that the largest variation of aerosol output comes from a single engine, the OM470 which shares most of its design with the other two heavy-duty engines but has the lowest engine displacement amongst them.

Figure 10 shows aerosol concentrations and production rates normalized by the corresponding values of the OM471 at $1800 \mathrm{rpm}$. This facilitates comparisons in absolute concentration. The concentration data now show that aerosol properties are much more strongly affected by the engine type than by the speed of the engine. Depending on rpm, maximum differences between engines reach factors of up to about 5 in terms of number and up to 2 in terms of mass. The concentrations of the OM473 stand out in particular, because they are among the lowest of all four engines at the medium engine loads considered here, while at full load (Fig. 7) concentrations were the highest. This adds to the evidence that the BMEP has a much higher impact on blowby aerosol sources than the engine speed.

One further detail to note is that OM473 (green) and the OM934 (black) reverse the order of curves between mass

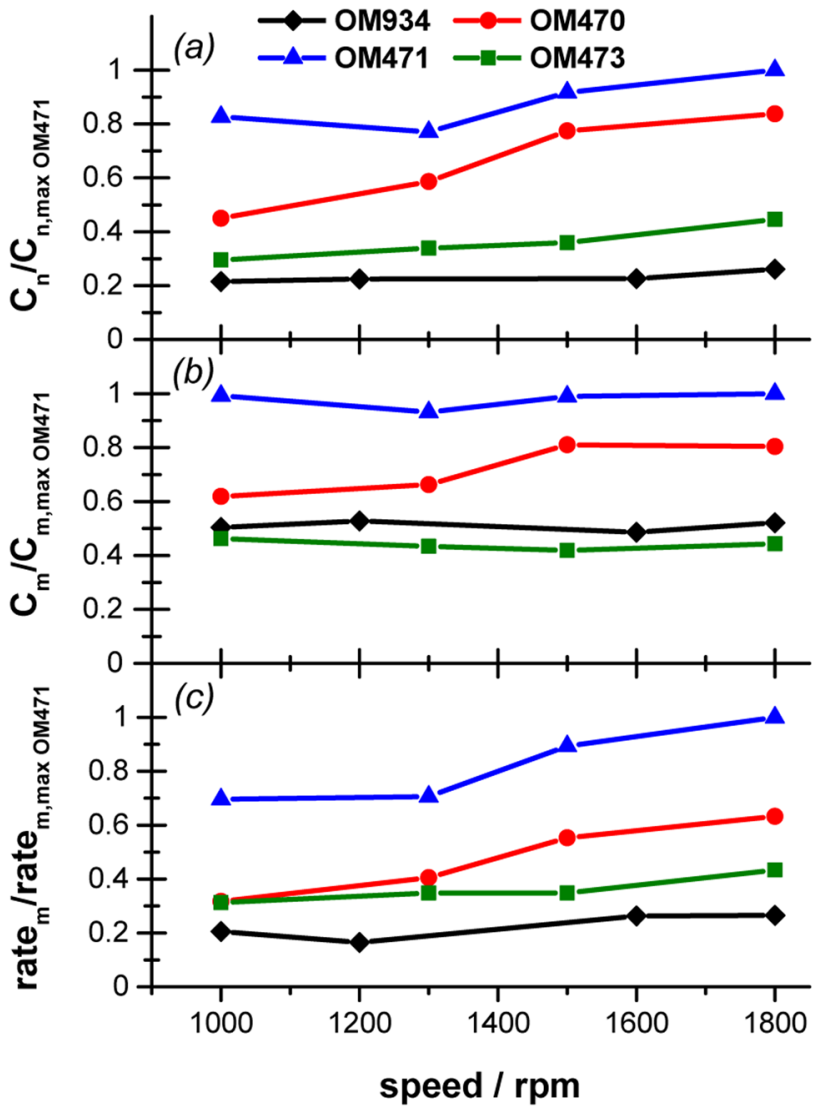

Fig. 10 Total aerosol number concentrations (a), mass concentrations (b) and mass flows (c) in the range $0.4-1.3 \mu \mathrm{m}$ vs. engine speed, data are normalized by total concentration/mass flow rate of the OM 471, data points are connected by straight lines as a guide to the eye

concentrations and mass flow rates, because the OM934 generates far less blow-by.

\section{Summary and conclusions}

In support of new engine designs with reduced crankcase aerosol emissions, this study corelates the design and operation of four diesel combustion engines with the respective blow-by aerosol characteristics. The selected engines represent the commercial vehicle engine portfolio of the Daimler Truck AG in Europe and include one medium-duty engine (OM934) and three heavy-duty engines (OM470, OM471, OM473).

The meaningful interpretation of crankcase aerosol data from different engines requires a uniform and well-reasoned basis of comparison. To that effect, engine oil and coolant temperatures were kept at comparable levels and similar engine oils were used. Aerosols were sampled from comparable positions and characterized with the same particle spectrometer using the sampling and dilution systems with 
known particle loss functions. The discussion of the data was facilitated also by comparing engines with multiple commonalities in design (and hence aerosol sources), but significant differences in terms of engine displacement. There was also a difference in piston material. The effect of engine operation on the aerosol production was evaluated on the basis of BMEP and engine speed, to permit comparing engines of different size and power.

Initial measurements of blow-by aerosol properties were based on a combination of two aerosol spectrometers (EEPS and OPC) covering a joint size range from about $6 \mathrm{~nm}$ to $10 \mu \mathrm{m}$. Subsequent detailed analyses of the size spectra from different engines showed however, that the bulk of aerosol mass was located above about $0.4 \mu \mathrm{m}$. (In terms of number, that range extended to about $0.05 \mu \mathrm{m}$.) It was therefore decided to limit engine comparisons to the range of $0.4-1.3 \mu \mathrm{m}$. This range is shown to contain the critical portion of the blow-by aerosol mass requiring extensive efforts for removal. Moreover, aerosols in that range can be captured efficiently and reliably by a single device (the OPC) with a minimum of measuring artifacts due to losses in the sampling and dilution system or other interferences; and one avoids differences between engines in anisokinetic conditions at the probe that affect mainly the large droplets. Engine comparisons are thus limited to mass concentrations as well as total mass flow rates in that range.

It was found that the mass based particle size spectra of all four engines, when operated at lower-end speed with maximum load, were virtually identical in shape with relatively broad peaks around $0.7 \mu \mathrm{m}(\mathrm{OM} 47 \mathrm{x})$ to $1.0 \mu \mathrm{m}$ (OM934). This is a strong indication that they share the same internal aerosol generation processes and sources of droplet production. The total aerosol mass flow rate rose in proportion to engine displacement, presumably due to the larger amount of oil circulating within the engine. Mass concentrations below $0.4 \mu \mathrm{m}$ were insignificant. However, the maximum number concentration always peaked around $0.4 \mu \mathrm{m}$. Number concentrations differed between engines by a factor of up to six, presumably because differences in design have an impact on how engine operation affects aerosol generation via key parameters such as internal temperatures, pressures and flows.

At BMEPs $\leq 10$ bar all four engines were found to exhibit similarly low aerosol concentrations (both in number and mass). With increasing engine load, concentrations began to increase rapidly by factors between about 2 (for the OM934) and more than 10 (OM473). This increase with BMEP can be approximated quite accurately by an exponential function. It is worth noting that the OM934, the engine with the weakest load dependence, featured an aluminum alloy piston, had the smallest displacement, the lowest peak BMEP, and the lowest maximum oil temperature. Note also that a previous study [17] had shown that the turbo charger aerosol contribution-although highly load dependent-adds no more than $21 \%$ to the aerosol mass concentration in the size range considered here.

Compared to the influence of engine load, increasing the engine speed from 1000 to $1800 \mathrm{rpm}$ caused only a minor increase in aerosol mass concentration (by a factor of less than 1.2), but affected blow-by flows, hence leading to a twofold increase aerosol mass flow. With regard to concentration, the increase in mechanical generation of blow-by aerosols with engine speed is apparently compensated to a large extent by the diluting effect of the rising blow-by flow. The aerosol mass flow on the other hand increased with engine speed because the blow-by flow flushes out oil droplets from the lower crankcase towards the sampling probe.

These facts point to three significant mechanisms of blow-by aerosol generation within the engine that are especially load sensitive: first, the conversion of oil vapor to aerosol, due to the exponentially increased availability of vapor at higher temperatures, especially in the piston environment (compare the oil vapor concentration data in [20]). Second, the increased production of micron size aerosols by the crankshaft and piston bearings when the lubricated gaps are compressed at higher loads. And third, the increased atomization with BMEP of oil by blow-by gas leakage at the piston rings. Each of these sources merits a more detailed investigation which is beyond the scope of this paper.

Acknowledgements The authors gratefully acknowledge the financial and technical support from Daimler Truck AG, Liebherr-International S.A., MAHLE GmbH, MTU Friedrichshafen GmbH, and UT99 AG, the members of the Engine Crankcase Emissions Consortium at the KIT.

Funding Open Access funding enabled and organized by Projekt DEAL.

\section{Declarations}

Conflict of interest On behalf of all authors, the corresponding author states that there is no conflict of interest.

Open Access This article is licensed under a Creative Commons Attribution 4.0 International License, which permits use, sharing, adaptation, distribution and reproduction in any medium or format, as long as you give appropriate credit to the original author(s) and the source, provide a link to the Creative Commons licence, and indicate if changes were made. The images or other third party material in this article are included in the article's Creative Commons licence, unless indicated otherwise in a credit line to the material. If material is not included in the article's Creative Commons licence and your intended use is not permitted by statutory regulation or exceeds the permitted use, you will need to obtain permission directly from the copyright holder. To view a copy of this licence, visit http://creativecommons.org/licenses/by/4.0/. 


\section{References}

1. Ahlborn, S., Blomerius, H., Schumann, H.: Neue wege in der reinigung von kurbelgehäuseentlüftungsgasen. MTZ Motortech Z 60(7-8), 454-459 (1999). https://doi.org/10.1007/BF03226523

2. Bendl, K., Gorbach, G., Gruhler, T., Coolens, H.: Leichte kunststoff-ventilhaube mit integrierter ölabscheidung. MTZ Motortech Z 71(4), 272-277 (2010). https://doi.org/10.1007/BF03225565

3. Uy, D., Storey, J., Sluder, C.S., Barone, T., Lewis, S., Jagner, M.: Effects of oil formulation, oil separator, and engine speed and load on the particle size, chemistry, and morphology of diesel crankcase aerosols. SAE Int. J. Fuels Lubr. 9(1), 224-238 (2016). https://doi.org/10.4271/2016-01-0897

4. Ueberschär, D., Schulmeyer, D., Parr, J.S., Keller, A.: Messung des ölverbrauchs von abgasturbolader und luftpresser. ATZ Extra 19(1), 26-29 (2014). https://doi.org/10.1365/s35778-014-1244-2

5. Enderich, A., Kissner, G., Ruppel, S., Özkaya, Y.: Highly efficient oil separation systems for minimised oil carry over. MTZ Worldw 69(4), 32-37 (2008). https://doi.org/10.1007/BF03226902

6. Golkarfard, V., Subramaniam, R., Broughton, J., King, A., Mullins, B.: Comparative performance of 12 crankcase oil mist separators. SAE Int. J. Engines 12(1), 5-14 (2019). https://doi.org/10. 4271/03-12-01-0001

7. Gruber, C., Pröll, T., Trojer, M., Adolf, I.: Optimisation of crankcase ventilation for large diesel and gas engines. MTZ Worldw 76(4), 18-23 (2015). https://doi.org/10.1007/s38313-014-1025-8

8. Heil, B., Teigeler, M., Sladek, W., Öing, H., Arndt, S., Melcher, S.: The new daimler heavy commercial vehicle engine series. MTZ Worldw 70(1), 4-11 (2009). https://doi.org/10.1007/BF032 27920

9. Herrmann, H.-O., Nielsen, B., Gropp, C., Lehmann, J.: MercedesBenz medium-duty commercial engines. MTZ Worldw 73(10), 4-11 (2012). https://doi.org/10.1007/s38313-012-0220-8

10. Hinds, William C. (2012): Aerosol Technology. Properties, Behavior, and Measurement of Airborne Particles. 2. Aufl. s.1.: Wiley-Interscience.

11. Hinzte, S., Janssen, H., Karl, W., Soares, J.: Cylinder head covers with integrated, switched cyclone-type oil mist separator. MTZ Worldw 67(5), 25-26 (2006). https://doi.org/10.1007/BF032 27845

12. Johnson, B.T., Hargrave, G.K., Reid, B., Page, V.J.: Crankcase sampling of $\mathrm{PM}$ from a fired and motored compression ignition engine. SAE Int. J. Engines 4(2), 2498-2509 (2011). https://doi. org/10.4271/2011-24-0209

13. Johnson, B.T.: Experimental analysis of crankcase oil aerosol generation and control. Loughborough University. Thesis (2012).https://hdl.handle.net/2134/10968

14. Reif, K. (Hg.): Abgastechnik für verbrennungsmotoren. Springer Fachmedien, Wiesbaden (2015) https://doi.org/10.1007/ 978-3-658-09522-2

15. Kulkarni, P., Baron, P.A., Willeke, K.: Aerosol measurement. John Wiley \& Sons Inc, Hoboken, NJ, USA (2011)

16. Sauter, H.L., Trautmann, P., Abendschein, M.: Messung und abscheidung von ölnebelaerosolen aus der kurbelgehäuseentlüftung von verbrennungsmotoren. MTZ Motortech Z 62(1), 80-83 (2001). https://doi.org/10.1007/BF03227084

17. Lorenz, M., Koch, T., Kasper, G., Pfeil, J., Nowak, N.: Origin and separation of submicron oil aerosol particles in the blow-by of a heavy-duty diesel engine. SAE Int. J. Engines (2020). https://doi. org/10.4271/03-13-03-0024
18. Janßen, M., Ruppel, S., Fukusen, T., Nonaka, A.: Systematische optimierung der kurbelgehäuseentlüftung in turbogeladenen benzin- und dieselmotoren. In: Liebl, J. (ed.) Ladungswechsel im Verbrennungsmotor 2016. Elektrifizierung-Potenziale für den Ladungswechsel-9. MTZ-Fachtagung. Springer Vieweg, Wiesbaden (2017)

19. Meinig, U., Pietschner, S., May, T.: Crankcase ventilation in current and future vehicle engines. MTZ Worldw 65(11), 19-22 (2004). https://doi.org/10.1007/BF03227713

20. Nowak, N., Scheiber, K., Pfeil, J., Meyer, J., Dittler, A., Koch, T., et al.: Sampling and conditioning of engine blow-by aerosols for representative measurements by optical particle counters. J Aerosol Sci 148, 105612 (2020). https://doi.org/10.1016/j.jaero sci.2020.105612

21. Nielsen, B., Sladek, W., Müller, M., Eberle, F.: The latest heavyduty engine generation from Mercedes-Benz-part 1: aims and design. MTZ Worldw 77(6), 48-53 (2016). https://doi.org/10. 1007/s38313-016-0039-9

22. Sauter, H., Brodesser, K., Brüggemann, D.: Hocheffizientes ölabscheidesystem für die kurbelgehäuseentlüftung. MTZ Motortech Z 64(3), 180-184 (2003). https://doi.org/10.1007/BF03226688

23. Tatli, E., Clark, N.: Crankcase particulate emissions from diesel engines. SAE Int. J. Fuels Lubr. 1(1), 1334-1344 (2009). https:// doi.org/10.4271/2008-01-1751

24. Michler, T., Dörnhöfer, J., Erforth, D., Heinz, A., Scheiber, K., Weber, P., et al.: Comparison of different particle measurement techniques at a heavy-duty diesel engine test Bed. In: SAE technical paper series. 14th international conference on engines and vehicles, SEP. 15, 2019. SAE International400 Commonwealth Drive, Warrendale, PA, United States (2019). https://doi.org/10. 4271/2019-24-0158

25. Vincent James, H.: Aerosol sampling. Science, standards, instrumentation and applications. John Wiley \& Sons Ltd, Chichester, UK (2007)

26. Wang, X., Grose, M.A., Caldow, R., Osmondson, B.L., Swanson, J.J., Chow, J.C., et al.: Improvement of engine exhaust particle sizer (EEPS) size distribution measurement-II. Engine exhaust particles. J. Aerosol Sci. 92, 83-94 (2016). https://doi.org/10. 1016/j.jaerosci.2015.11.003

27. Wang, X., Grose, M.A., Avenido, A., Stolzenburg, M.R., Caldow, R., Osmondson, B.L., et al.: Improvement of engine exhaust particle sizer (EEPS) size distribution measurement-I. Algorithm and applications to compact-shape particles. J. Aerosol Sci. 92, 95-108 (2016). https://doi.org/10.1016/j.jaerosci.2015.11.002

28. Watter, H.: Hydraulik und pneumatik grundlagen und übungenanwendungen und simulation. Springer Fachmedien Wiesbaden, Wiesbaden (2017). https://doi.org/10.1007/978-3-658-18555-8

29. Krüger, W., Kleffel, J., Dietrich, P., Koch, D.: 1.07-L daimler HD truck engine for euro VI and tier 4. MTZ Worldw 73(12), 4-10 (2012). https://doi.org/10.1007/s38313-012-0246-y

30. Zitarosa, F., Zedelmair, P., Erdmann, C., Schneider, J.: Adaptive oil separation for efficient crankcase ventilation. MTZ Worldw 76(6), 28-31 (2015). https://doi.org/10.1007/s38313-015-0018-6

Publisher's Note Springer Nature remains neutral with regard to jurisdictional claims in published maps and institutional affiliations. 